International Journal of Linguistics, Literature and Translation

ISSN: 2617-0299 (Online); ISSN: 2708-0099 (Print)

DOI: $10.32996 / \mathrm{ijllt}$

Journal Homepage: www.al-kindipublisher.com/index.php/ijltt

\title{
The Stylistic Features of the Isolated Voice Attributed to the Poetical Work "Fragments of a Woman" by Suad Al-Sabbah as a Model
}

\section{Nassim Assadi}

Assistant Professor of Arabic Language and literature, Department of Arabic Language and Literature, Sakhnin Academic College for Teacher Education Sakhnin, 2173 Israel

\ Corresponding Author: nw626@hotmail.com, E-mail: nw626@hotmail.com

\section{ARTICLE INFORMATION ABSTRACT}

Received: September 08, 2021

Accepted: October 14, 2021

Volume: 4

Issue: 5

DOI: $10.32996 /$ ijllt.2021.4.10.22

\section{KEYWORDS}

Stylistic features, Isolated sound, Explosive sounds, Fricatives, Suad Al-Sabbah, Inner Rhythmicity, Poetic meter.
The stylistic features of isolated sound are an integral part of the inner rhythmicity of the text, and the inner rhythmicity constitutes a part of the acoustic structures that help reveal the vocal implementation to embody the imagination and achieve the image in the text at large. The criterion we adopted in our analysis of the stylistic features of the isolated voice attributed to the poetical work "Fragments of a Woman" by Suad Al-Sabbah is the ratio of whispered sounds on the one hand to its counterparts of fricatives and explosive sounds on the other hand, and the extent to which this ratio exceeds its ratios in normal speech. We were able to observe that the proportions of the presence of different sounds in the poems are commensurate with the emotional and moral connotations within them. The percentage of whispered sounds in the poems exceeded its proportion in ordinary speech when the poet was dominated by the feelings of weakness and fear for challenging the established social constants and norms or as a result of the feelings of sorrow and sadness that the poet lives in the life of repression and injustice. Nonetheless, this percentage was notably lower when the poet covered her revolution by expressing her pride in her homeland or background. The presence of the explosive sounds in a higher percentage compared to fricatives might be attributed to the fact that the entire poetic work is an all-encompassing revolution against numerous constants and long-standing concepts of the Eastern society, and one of the means of expressing the revolution linguistically is the high-rate of explosive sounds.

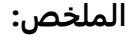

يقوم هذا المقال ببحث السّمات الأسلوبيّة للصّّوت المعزول في ديوان فيّان فتافيت امرأة لسعاد الصّبّاح،

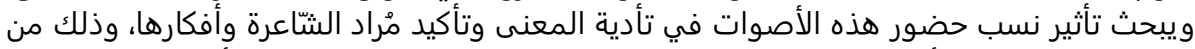

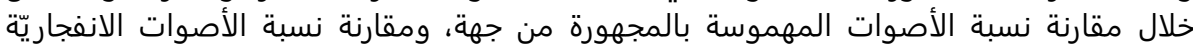

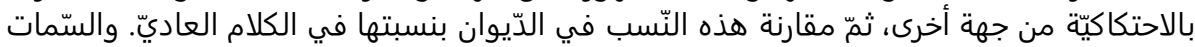

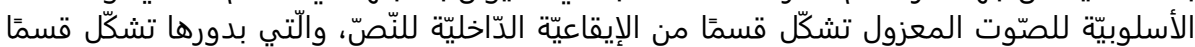

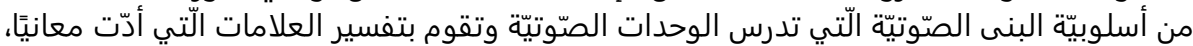

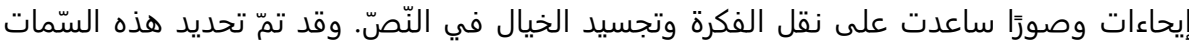

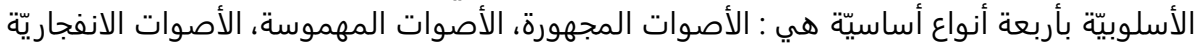

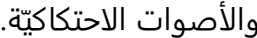

الكلمات المفتاحية: السّمات الأسلوبيّة، الصّوت المعزول، الأصبّة الصوات الإنة الانفجاريّة، الأصوات الاحتكاكيّة،

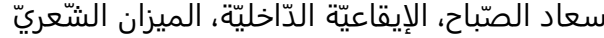

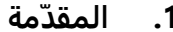

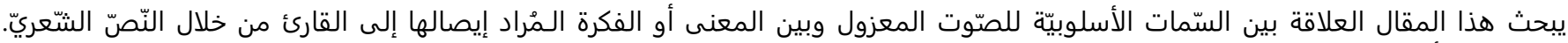

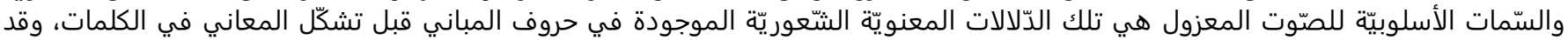

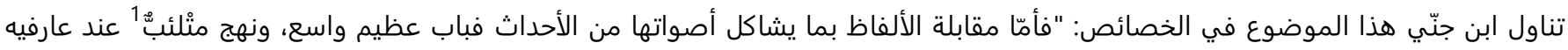




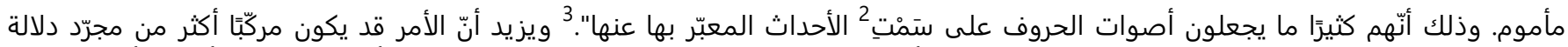

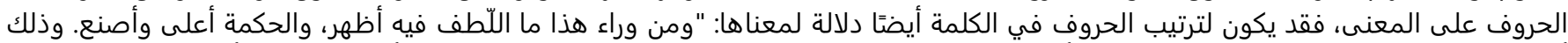

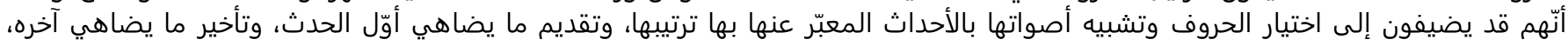

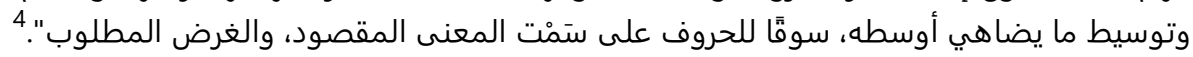

ويعلّق عبّاس على قول ابن جنّي: "إنّ الإنسان العربيّ بعد أن يختار الحروف الّتني تتوافق أصواتها مع الحدث الّاّي الّي يريد التّعبير عنه، يقوم بترتيبها

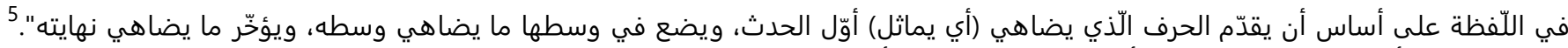

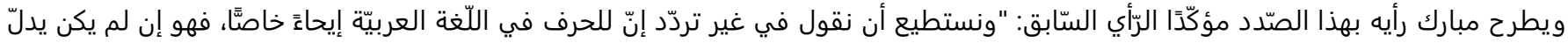

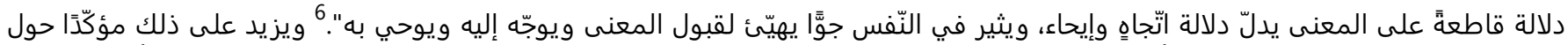

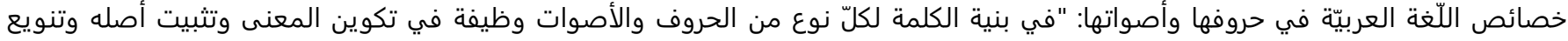

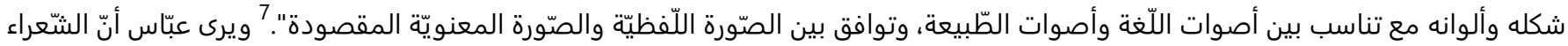

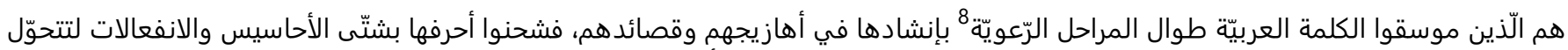

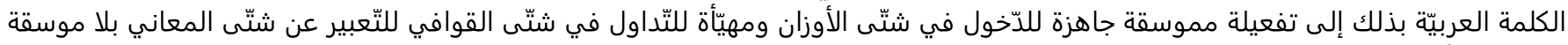

مصطنعة.9

ويرى السّعدنيّ أنّ هذه الظّاهرة ناتجة عن "التّكرار الحرّ، وهو قانون فعليّ يكتسب حتميّته من محدوديّة الرّموز (الفونيمات) في أيّة لغة، ومن القدرة القدّة

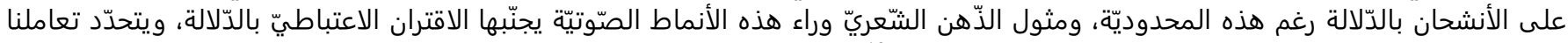

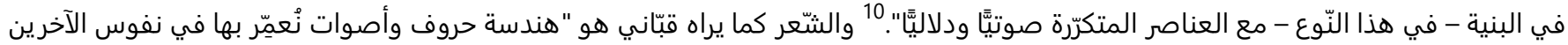

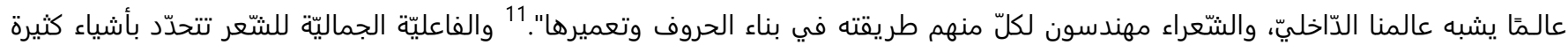

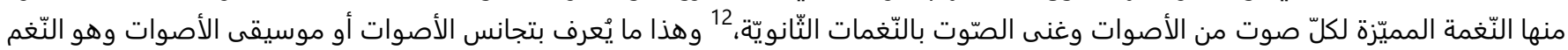

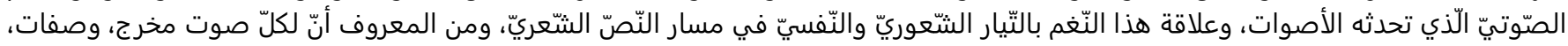

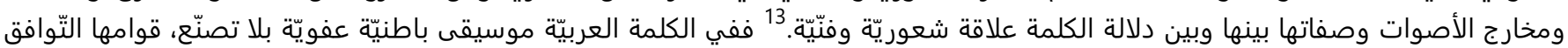

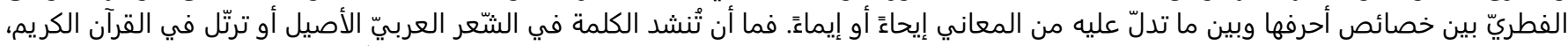

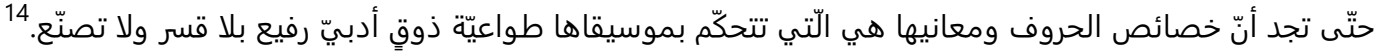

2 2. المشاريع ذات العلاقة

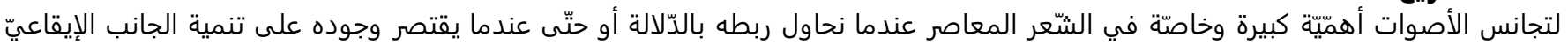

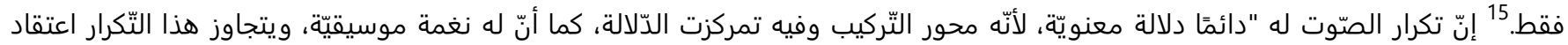

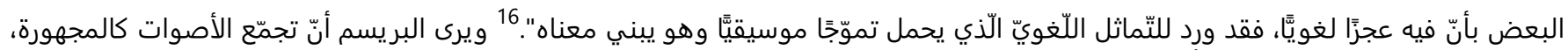

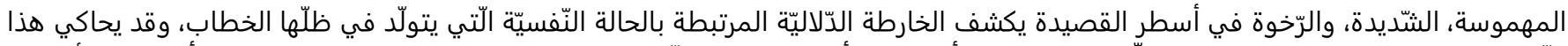

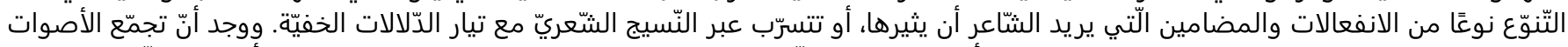

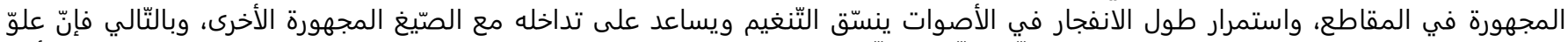

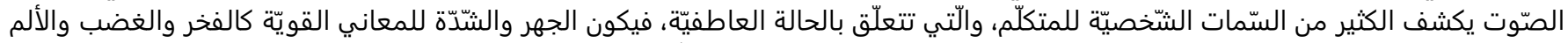

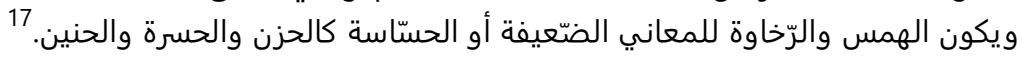

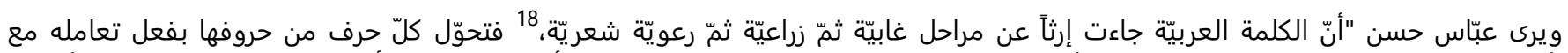

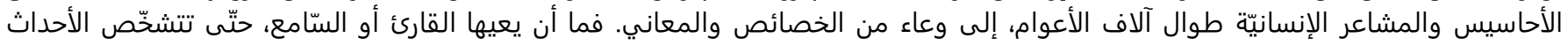

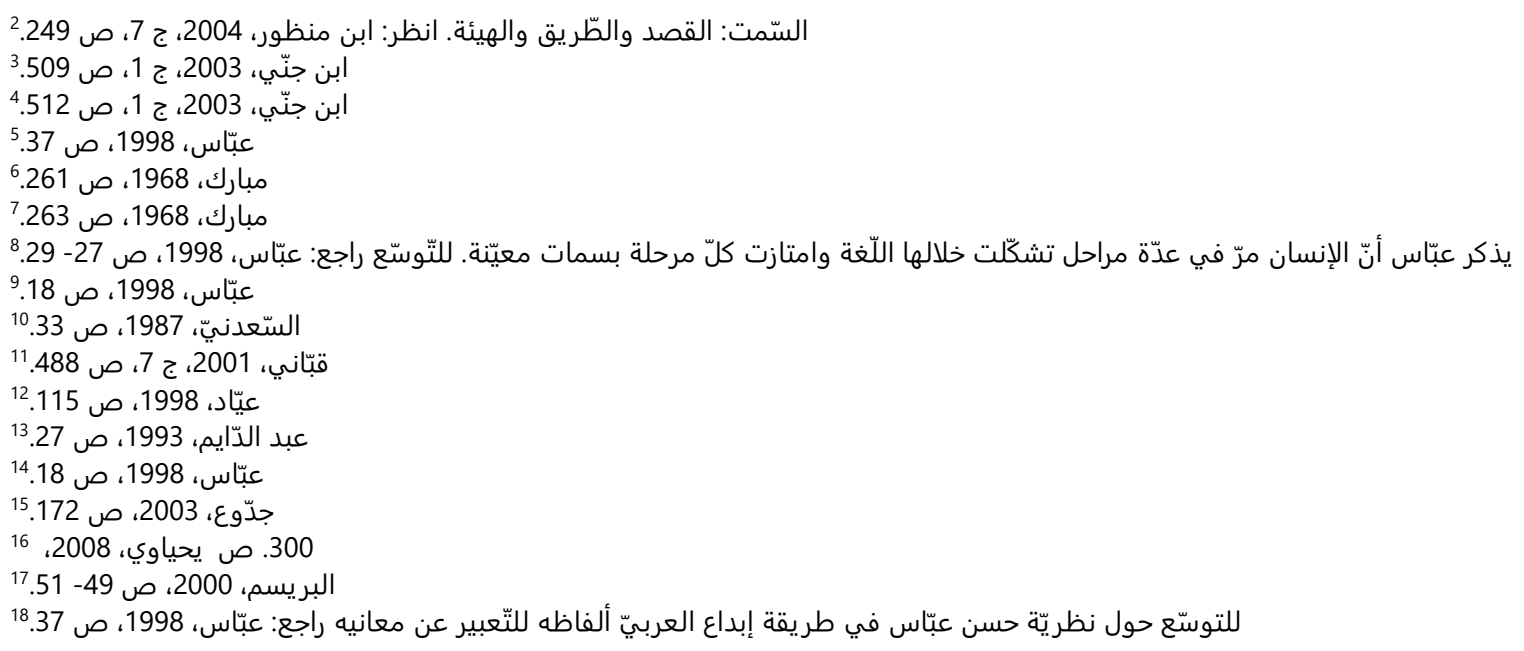


والأشياء والحالات في مخيّلته أو ذهنه أو وجدانه، وبذلك ينوب الحرف في العربيّة عن الكلمة وتنوب الكلمة عن الجملة". 19 ولم تخل الدّراسات

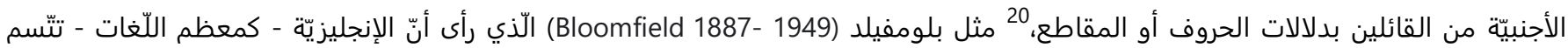

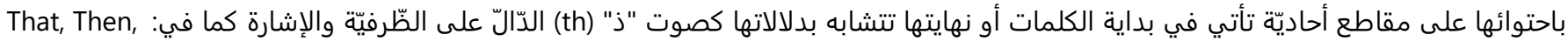

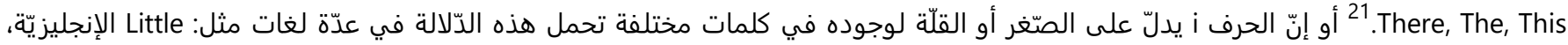

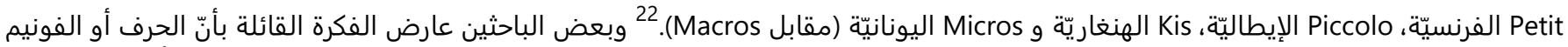

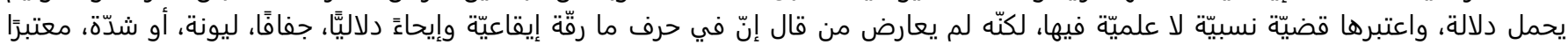

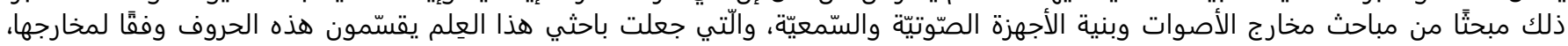

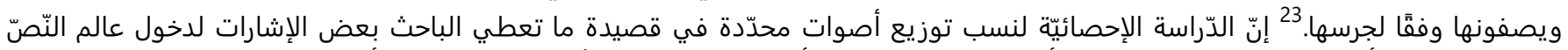

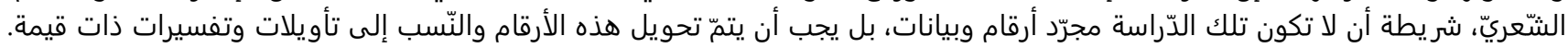

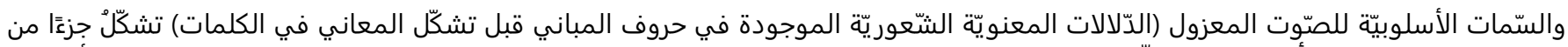

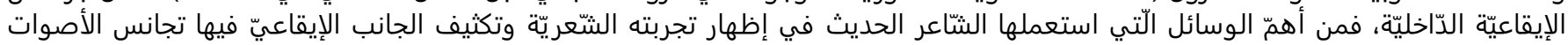

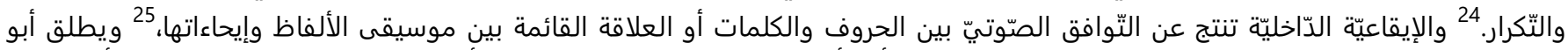

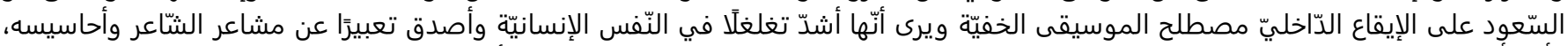

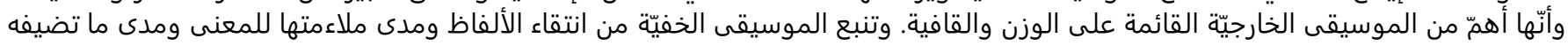

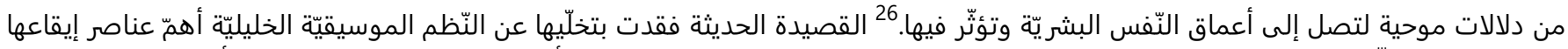

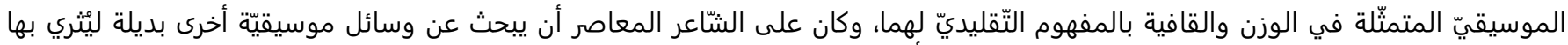

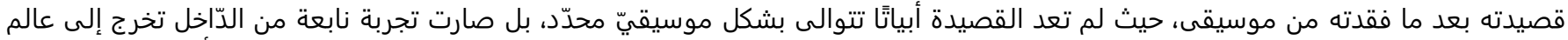

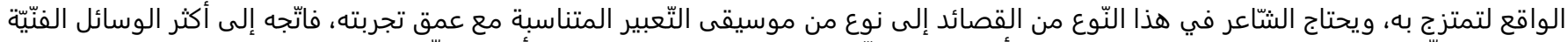

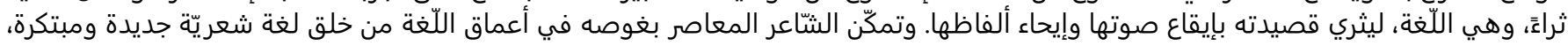

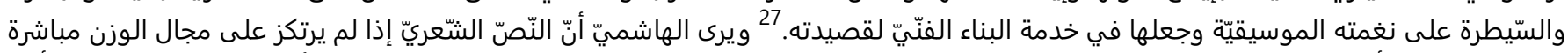

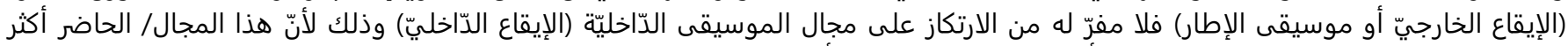

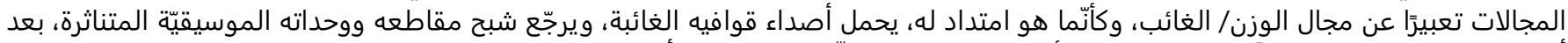

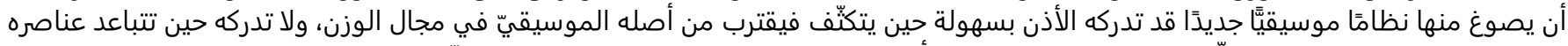

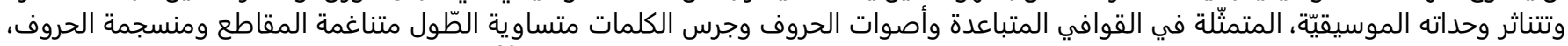

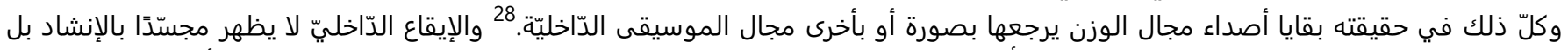

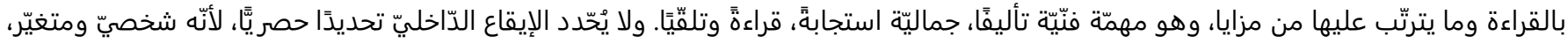

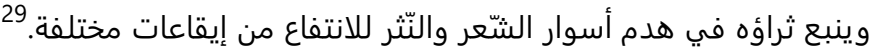

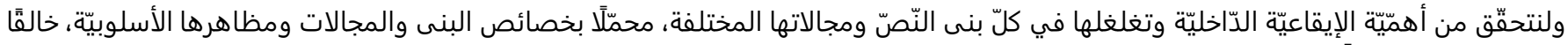

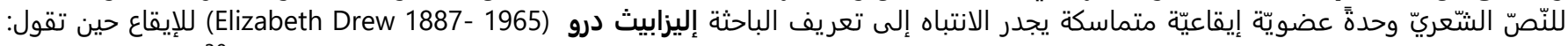

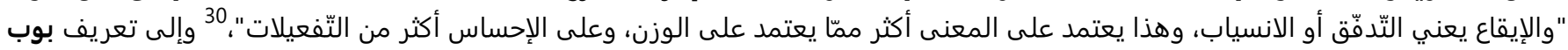
(Alexander Pope 1688-1744)

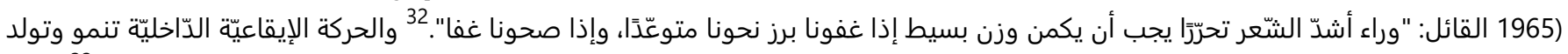

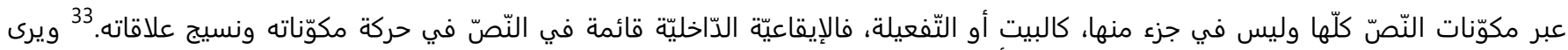

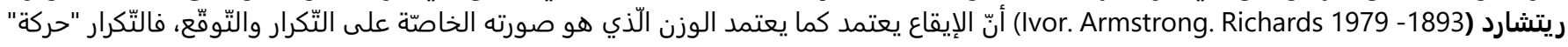

\footnotetext{
عبّاس، 1998، ص ص 29 .

20 Hershev.250 -234، 2008،

${ }^{21}$ Bloomfield, L. 1954, pp $244-245$.

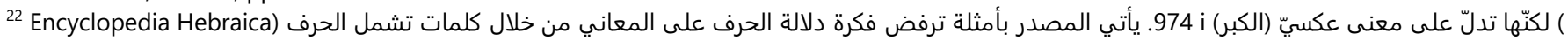

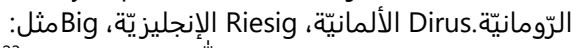

عطا الله، 2000، صن ص2003.

جدّوع، 2003، 2003، ص 2000

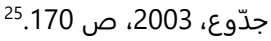

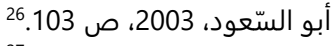

جدّوع، 2003، ص 169 169- 170.

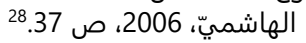

الصّكر، 2010، ص 2006 40- 41.

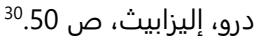

درو، إليزابيث، ص 19

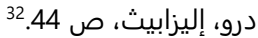

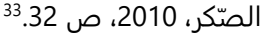


في الصّّوت، والتّوقّع يعني "انتظام" هذه الحركة كيفيّة معيّنة، وليس شرطًا أن يحدث ما تتصوّره بالفعل، والشّعور وتوقّعه يرجع إلى حالة ذاتيّة

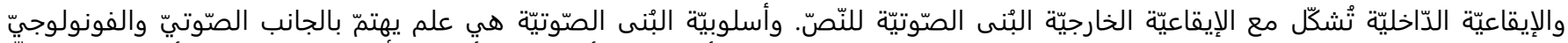

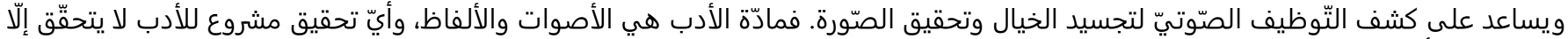

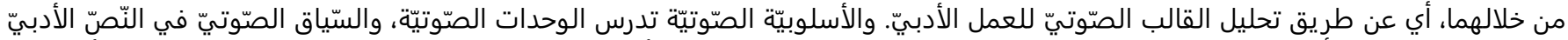

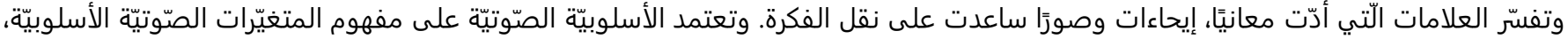

وبمقدار ما يكون للّغة حرّيّة التّصرّف ببعضائ إيحاءت العناصر الصّوتيّة للسّّلسلة الكلاميّة، بمقدار ما تستطيع أن تستخدم تلك العناصر لغايات أسلوبيّة. 35

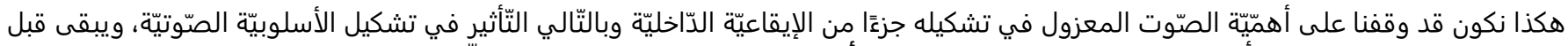

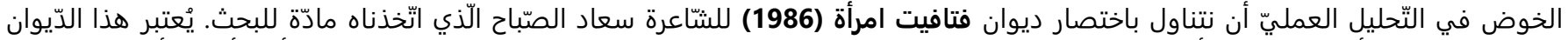

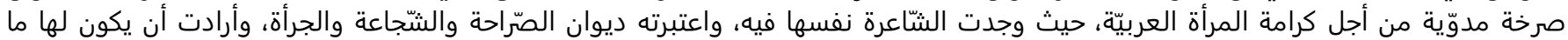

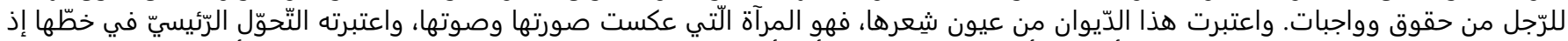

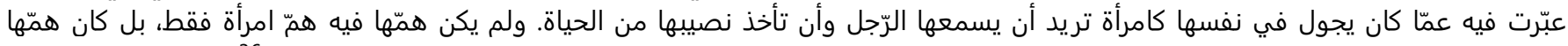

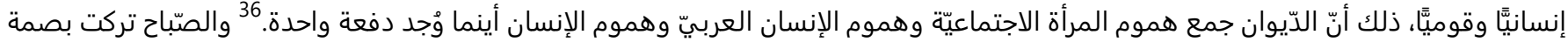

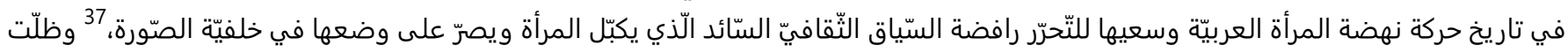

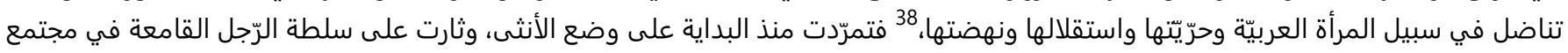
عربيّ ما يزال يعاني من عقد الذّكوريّة، وتمرّدت على تقاليد مجتمعيّة وأسريّة عفا عليّة اليها الزّمن. 39

3. الأدوات والبيانات (منهجيّة الدّراسة)

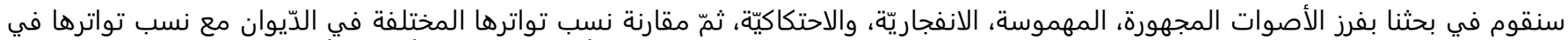

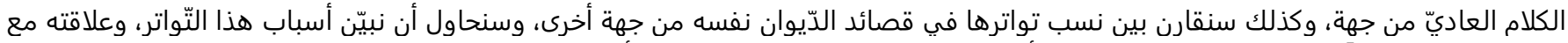

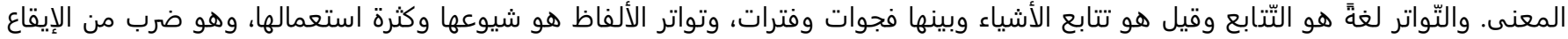
الدّاخليّ تنحو فيه القصيدة إلى الاستدارة وتخضع حركتها الدّاخليّة للتّداعي الصّوريّ.

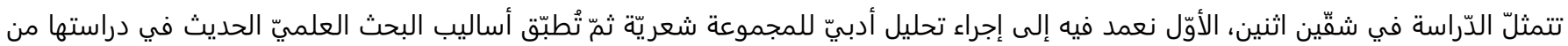

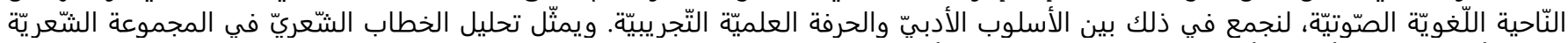

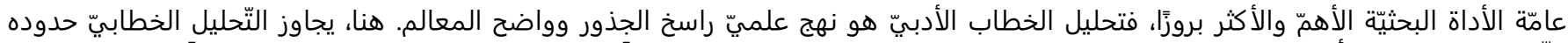

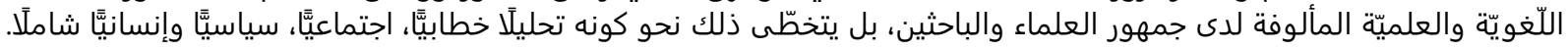

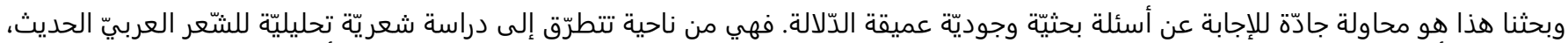

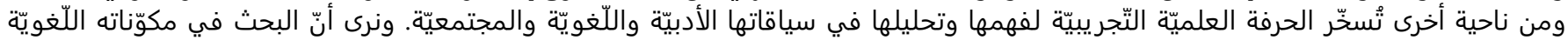
والبحثيّة يسعى للإجابة عن الأسئلة التّالية إجابة علميّة وموضوعيّة:

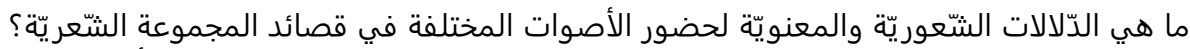

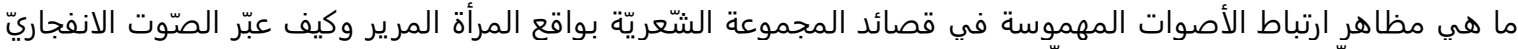

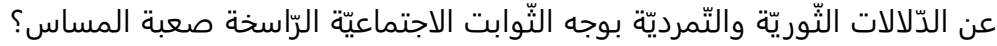

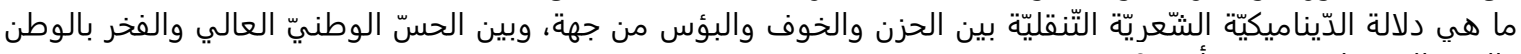
والبيئة المحيطة من جهة أخرى؟

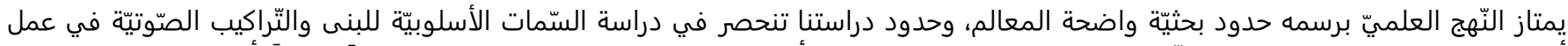

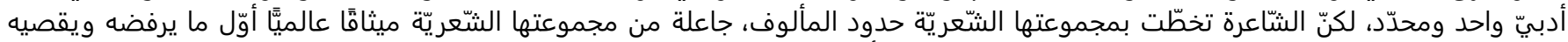

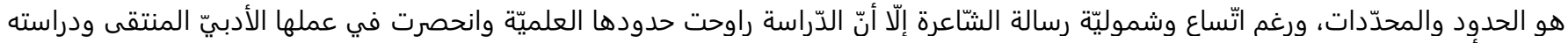

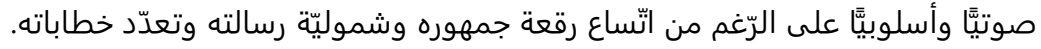

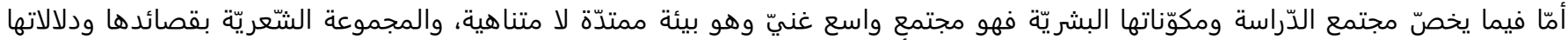

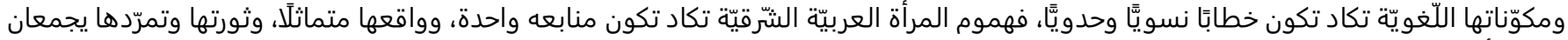

نساء الأرض جميعًا.

\footnotetext{
${ }^{34}$ Richards, 1930, p 134.

بن يحي، 2011، 2002

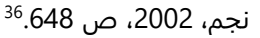

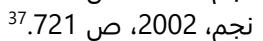

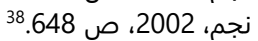

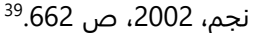




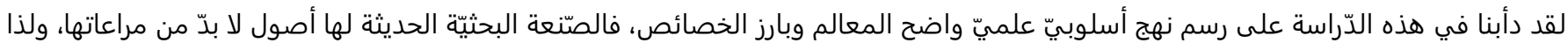

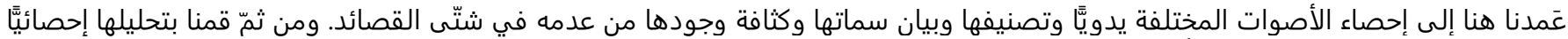

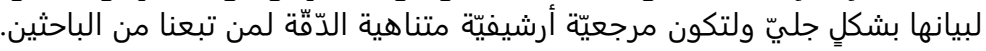

• • تمّ اختيار عمل أدبيّ عالي الجودة بعينه، وتمّت دراسته ومناقشته دراسة علميّة وأدبيّة وتحليليّة متعدّدة الوجوه والاعتبارات.

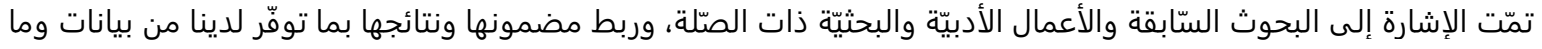
خلصنا إليه من نتائج. تمّ إجراء تحليل محتوى علميّ عميّ علميق للعمل الأدبيّ بعينه وللدّراسات السّابقة بصورة عامّة بما يدعم ما وصل إليه بحثنا من نتائج وما قدّمه من بيانات. وظّفنا أساليب النّقد الأدبيّ والتّحليل اللّغويّ الاجتماعيّ وتحليل الخطاب النّفسيّ وجمع البيانات والإحصائيّات وتصنيفها وتحليلها في أجزاء مختلفة من الدّراسة.

4. الأصوات المجهورة: 4.1

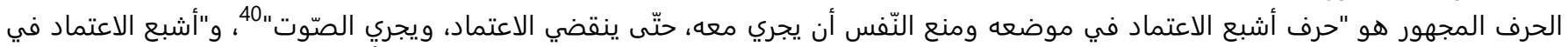

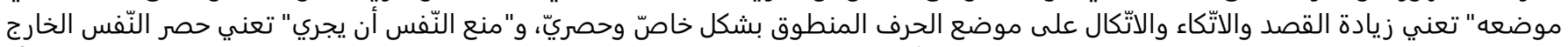

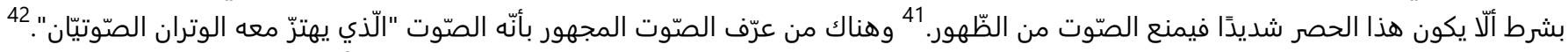

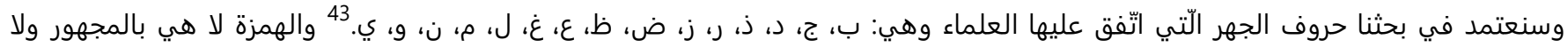
بالمهموس.

4.2 الأصوات المهموسة:

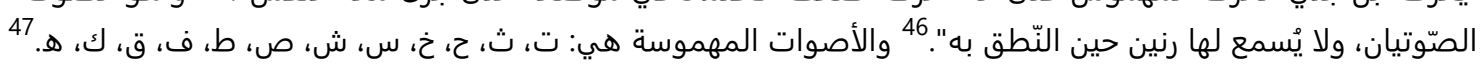

الحرف 4.3 الأصوات الانفجاريّة أو الشّديدة:

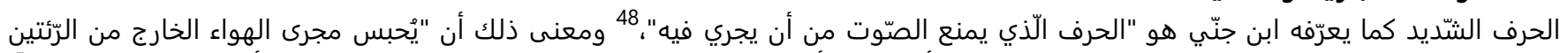

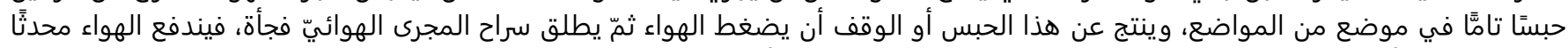

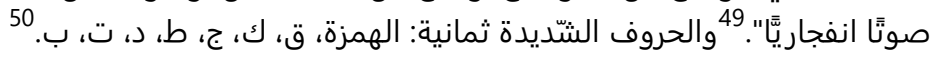

ابن جنّي، 1985، ص 190

قدّور، المجلّد 86، الجزء، 3. ص 1961، 1987.

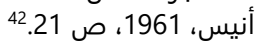

عبّاس، 1998، 199 ص 1961، صن 49.

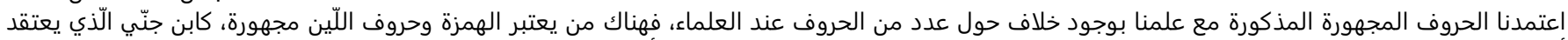

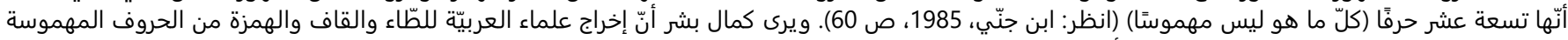

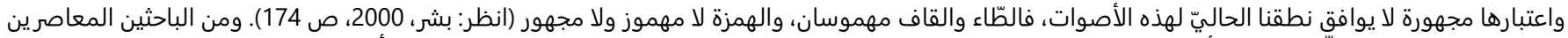

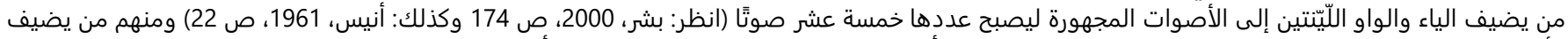

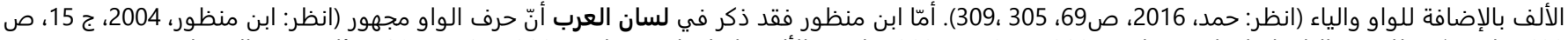

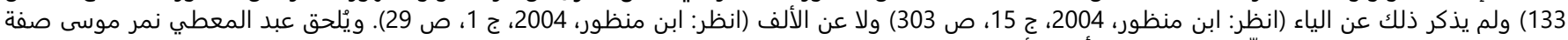

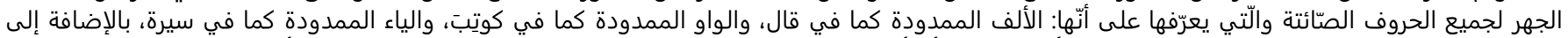

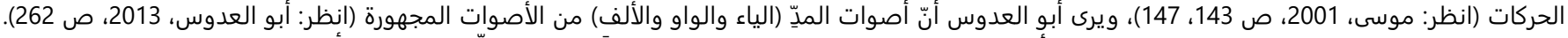

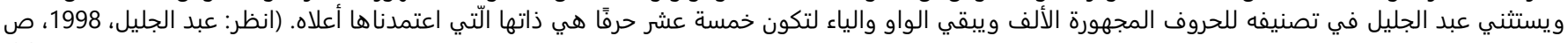
(36

بشر 2000، ص 175. وكذلك انظر: عبّاس، 1998، ص 95. وأيضًا: عبد الجليل، 1998، ص 1985، صـ 36.

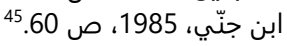

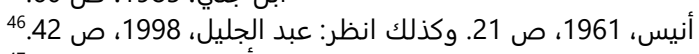

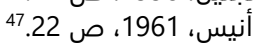

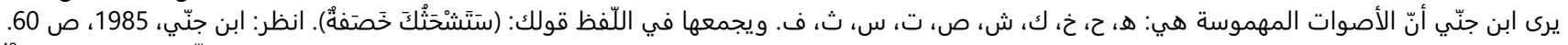

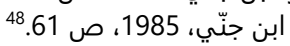

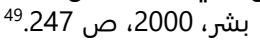

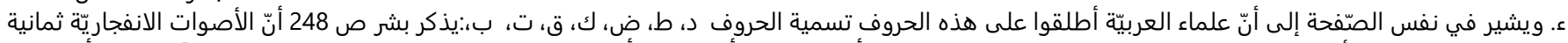

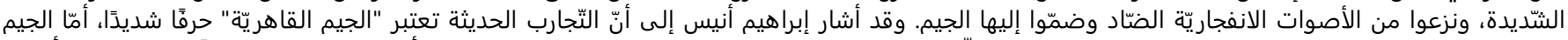

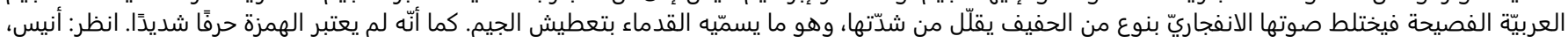

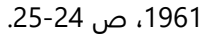

ابن جنّي، 1985، ص 61 ص 
(الأصوات الرّخوة أو الاحتكاكيّة:

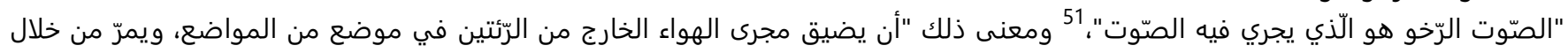

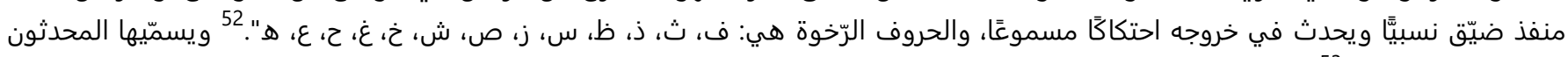
بالأصوات الاحتكاكيّة.

جدول (1): ملخّص لأنواع الحروف ونسبتها في ديوان فتافيت امرأة

\begin{tabular}{|c|c|c|c|c|c|c|}
\hline نسبّة الانفجاريّ إلى & $\begin{array}{r}\text { احتكاكيّ } \\
\text { (رخو) }\end{array}$ & انفجاريّ & إلى المجهور المهموس & مهموس & مجهور & القصيدة \\
\hline $4 \% 11$ & 222 & 253 & $40 \%$ & 249 & 624 & فيتو على نون النّسوة \\
\hline 03\%1 & 82 & 106 & $\% 37$ & 96 & 254 & المجنونة \\
\hline$\% 130$ & 186 & 249 & $\% 43$ & 246 & 570 & كويتيّة \\
\hline$\% 130$ & 257 & 342 & $\% 40$ & 279 & 736 & فتافيت امرأة \\
\hline \%120 & 164 & 197 & $\% 41$ & 207 & 504 & خليجيّة من مفكّرة امرأة \\
\hline$\% 148$ & 219 & 325 & $\% 78$ & 362 & 464 & توسّلات \\
\hline$\% 150$ & 123 & 190 & $\% 50$ & 189 & 374 & إلى تقدّميّ من العصور \\
\hline$\% 120$ & 243 & 308 & $\% 44$ & 302 & 682 & إلى رجلِ يخاف البحر \\
\hline$\% 160$ & 53 & 85 & $\% 34$ & 66 & 191 & العالم أنت \\
\hline$\% 135$ & 134 & 182 & $\% 48$ & 156 & 320 & الاتّفاق \\
\hline$\% 147$ & 72 & 106 & $\% 56$ & 107 & 190 & قهوة \\
\hline$\% 110$ & 68 & 76 & $\% 41$ & 77 & 186 & الإقامة الدّائمة \\
\hline$\% 120$ & 216 & 258 & $\% 40$ & 256 & 627 & أعقل المجانين \\
\hline$\% 93$ & 162 & 151 & $\% 42$ & 161 & 379 & شاي السّاعة الخامسة \\
\hline \%117 & 418 & 490 & $\% 39$ & 459 & 1156 & إنّّ جسمي العرب نخلة تشرب من \\
\hline \%98 & 338 & 332 & $\% 34$ & 311 & 909 & عند التّاصرأة ناصريّة إلى جمال \\
\hline$\% 130$ & 278 & 368 & $\% 40$ & 336 & 844 & وردة البحر \\
\hline$\% 97$ & 562 & 547 & $7 . \% 31$ & 534 & 1683 & وصل السّيف إلى الحلق \\
\hline $120 \%$ & 3797 & 4565 & $41 \%$ & 4393 & 10693 & مجموع كلّ فئة \\
\hline
\end{tabular}

جدول (2): بمجموع ونسبة الأصوات المختلفة في ديوان فتافيت امرأة

\begin{tabular}{|c|c|c|c|c|}
\hline الأصوات الاحتيّة & الأصفاريّة & الأصهموسة & المجهورة & 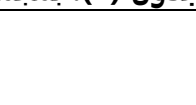 \\
\hline 3797 & 4565 & 4393 & 10693 & المجموع \\
\hline$\% 20.7$ & $\% 24.8$ & $\% 23 ، 9$ & $\% 58.3$ & النّسبة \\
\hline
\end{tabular}

عدد أحرف الدّيوان الملفوظة 18337حرفًا54

5. قراءة تأويليّة لتواتر الأصوات في الدّيوان:

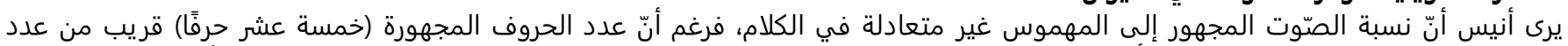

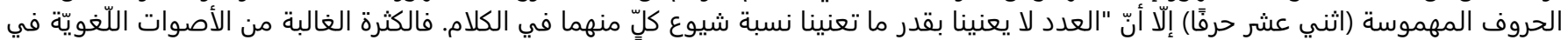

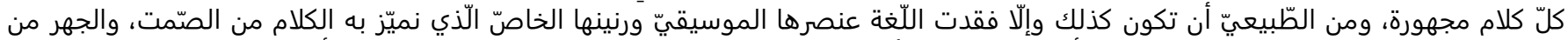

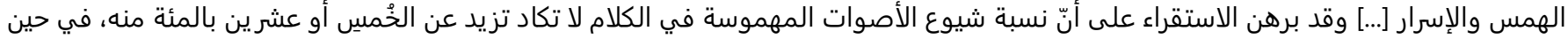

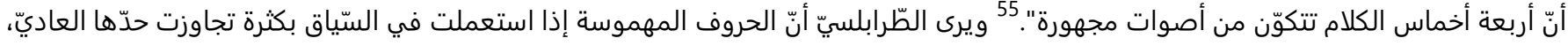

ابن جنّي، 1985، ص بـ 1900

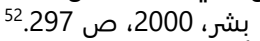

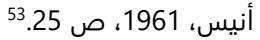

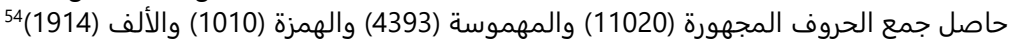

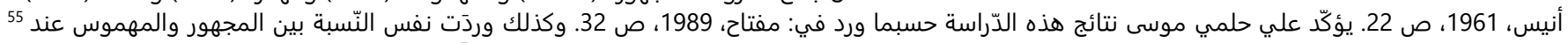

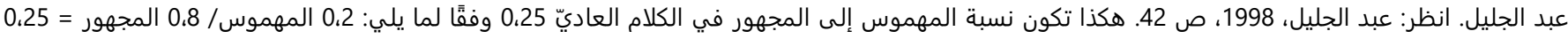
المهموس إلى المجهور. 
تضاعف الجهد وانحصر الاهتمام فيها وتعلّقت بها طاقة دلاليّة خاصّة، وذلك بسبب الجهد الإضافيّ الّذي تحتاجه هذه الحروف، لأنّها حروف مجهدة الذّاء

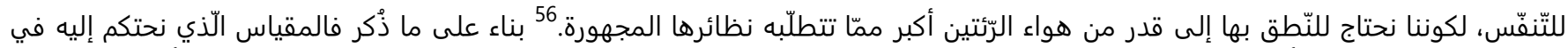

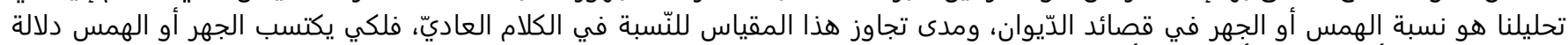

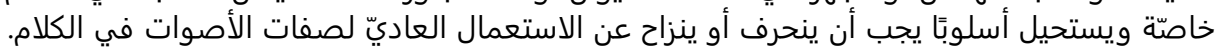

نسبة الأصوات المهموسة في ديوان فتافيت امرأة (23،9\%) وهي أعلى من نسبة الأصوات المهموسة في الكلام العاديّ (20\%)، ولعلّ لهذا دلالة

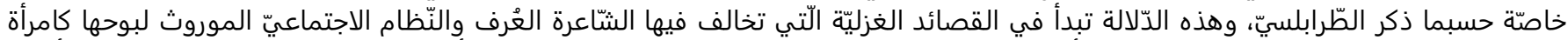

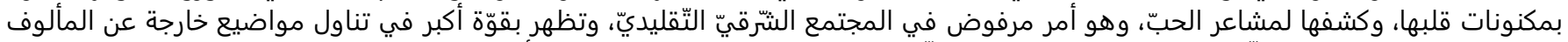

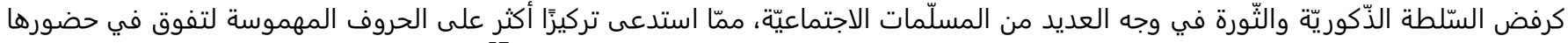

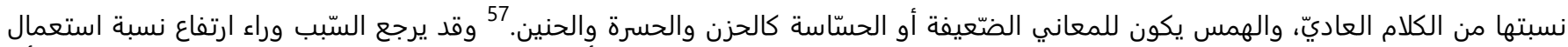

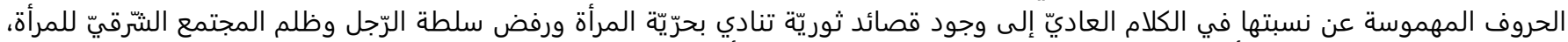

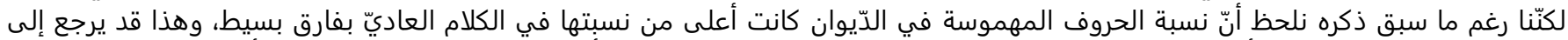

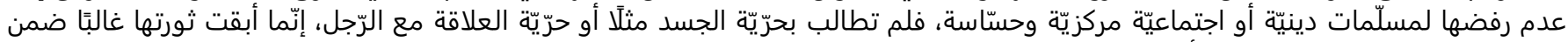
حرّيّة الخَيار والقول والتّعبير عن الرَّأي وحرِّيّة المشاعرك.

أعلى نسبة لتواتر الحروف المهموسة إلى المجهورة في الدّيوان كانت في قصيدة "توسّّلات" حيث تثور الشّاعرة على استعمار الرّجل وظلمه لها

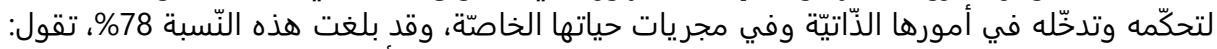
"أتوسّل إليك وند

أن لا تقف بين كتابي وبيني

بين ضوء عيني

وعيني

بين كحلي وهدبيني

بين فمي وصوتي وهربي

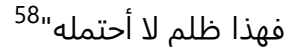

في قصيدة "قهوة" وهي قصيدة غزليّة تبوح فيها الشّاعرة بغراميّاتها معارضةً الرّواسخ الاجتماعيّة بلغت نسبة الحروف المهموسة إلى المجهورة

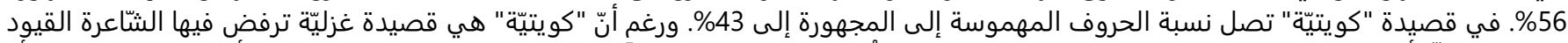

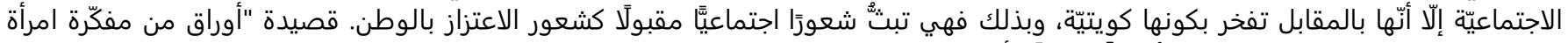

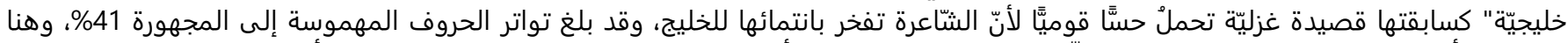

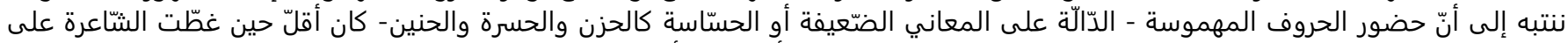

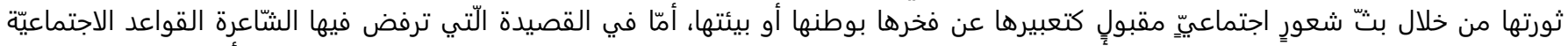

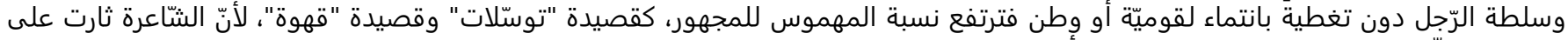

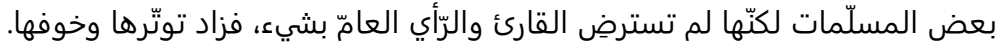

بعد فحصنا لنسب الحروف المهموسة في ديوان فتافيت امرأة تبيّن لنا أنّ لحرفي التّاء والهاء نسبة متساوية هي الأعلى بين الحروف المهموسة ثمّ المّاء

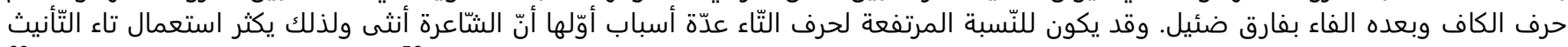

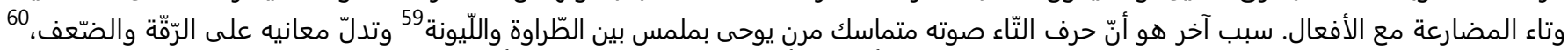

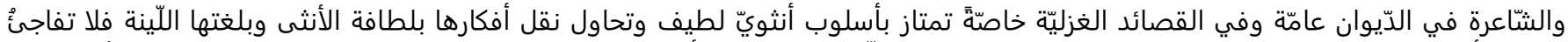

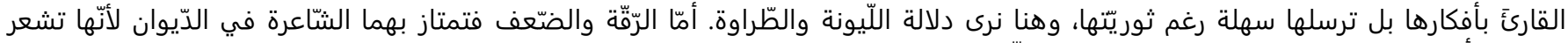
بضعفها أمام سلطة الرّجل (المحبوب) والمجتمع الذّكوريّ.

القصائد الغزليّة رغم ثوريّة أفكارها جاءت رقيقةً سلسةً أكثر من القصائد القوميّة أو السّياسيّة في الدّيوان، ولأنّ القصائد الغزليّة تمتاز برقّتّها وطراوتها

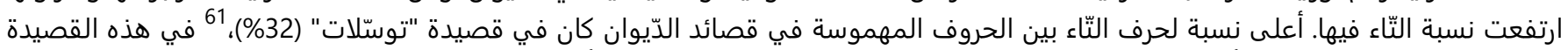

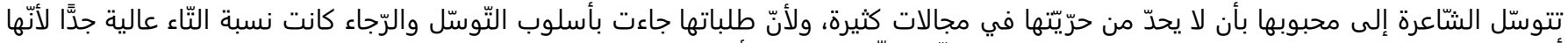

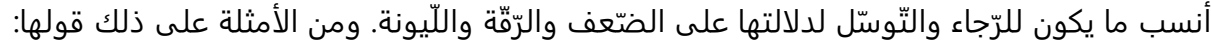

\footnotetext{
الطّرابلسيّ، 1996، ص 55. وقد أكّد البريسم صحّة هذه النّتائج. راجع: البريسم، 2000، ص $2000 ،$

البريسم، 2000، ص 2000

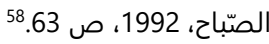

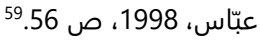

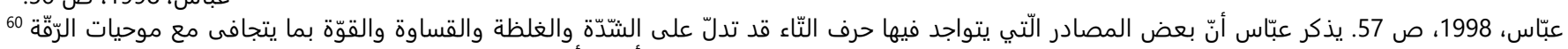

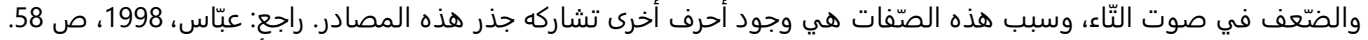

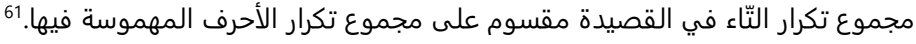




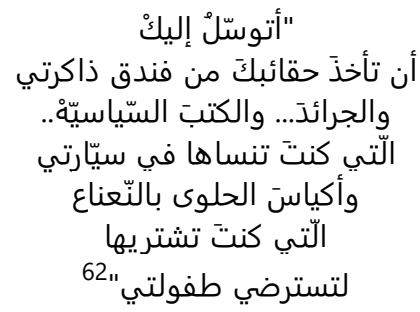

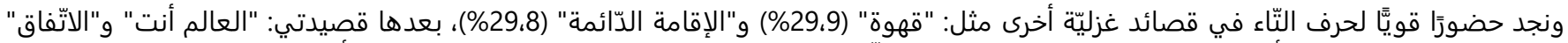

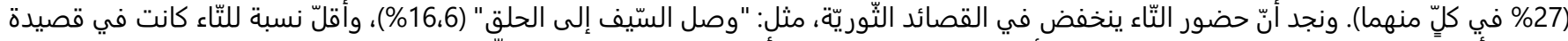

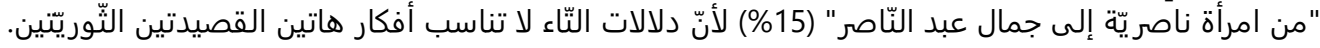

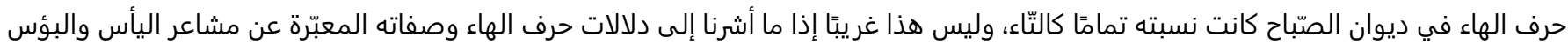

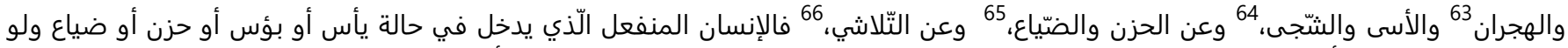

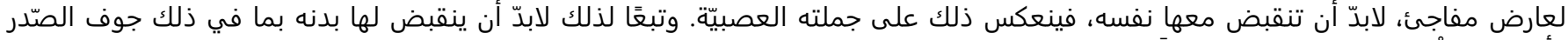

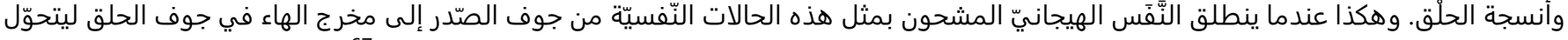

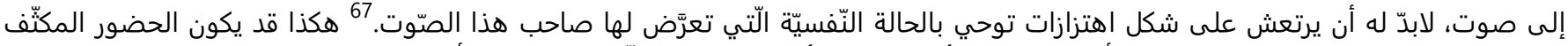

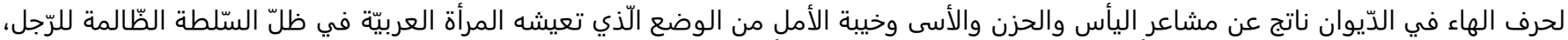

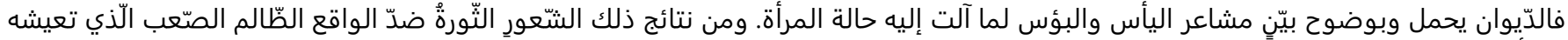

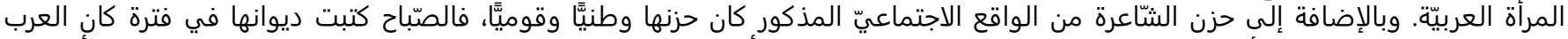

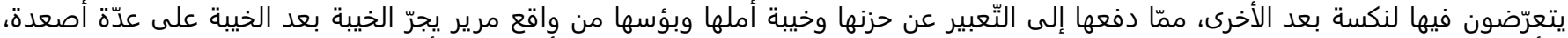

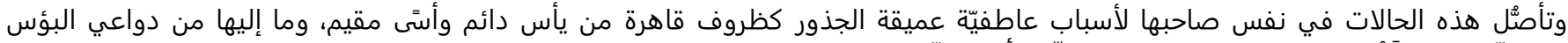

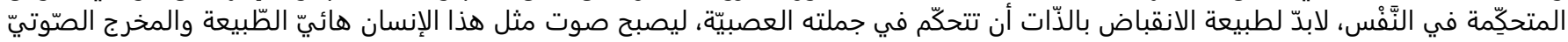

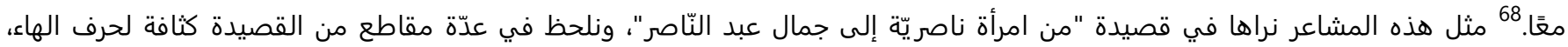
كقولها:

"كان هو الحلم الّذي يورق في أهدابنا

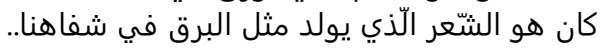

كان بنا يطير.. فوق جغرافيّة المكان المكان

مستهزيًا من هذه الحواجز المصطنعه..

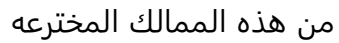

من هذه الملابس الضيّقة، المضحكة ...المرقّعه.

من هذه البيارق الباهية الألوان"69

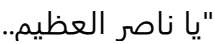

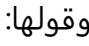

هل تقرأ في منفاك أخبار الوطن مؤج؟

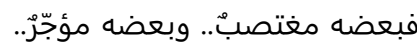

وبعضه مقطّعُ.. وبعضِ. وبعه مرقّعُ..

وبعضه مطبّعُ.. وبعضه مبعه منغلقُ...

وبعضه منفتحُ.. وبعضه وبعضه مسالمُ..

وبعضه مستسلمُ..

وبعضه ليس له سقفْ... ولا أبواب"70

إنّنا نجد مشاعر مختلطة من اليأس والبؤس والحزن لحال العرب بعد ناصر وفجعًا لفقده، وهكذا كان لحضور الهاء دور في تحقيق هذه المشاعر وتقوية المعاني المقصودة من خلال اللّفظ.

\footnotetext{
الصّباح، 1992، ص 1998 ، 62

عبّاس، 1998، 1998، ص 1992، 193

عبّاس، عبّاس، 1998، ص 1998، صب 194.

عبّاس، 1998، 1988، ص 1988، 193.

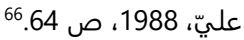

عبّاس، 1998، 1998، ص 1988، 197.

عبّاس، 1998، 1992، ص 1992، 198

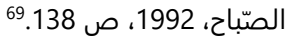

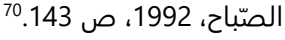




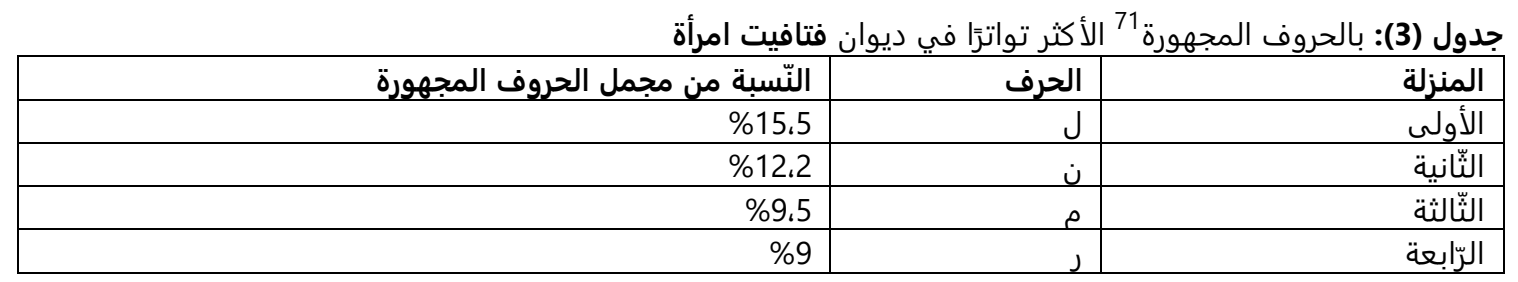

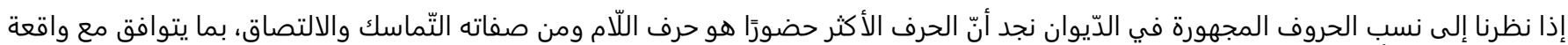

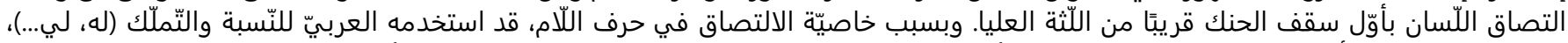

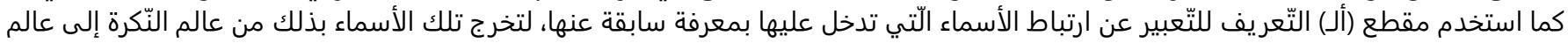

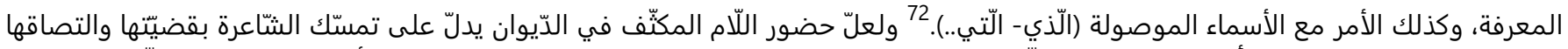

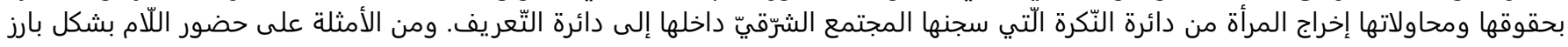
في الدّيوان:

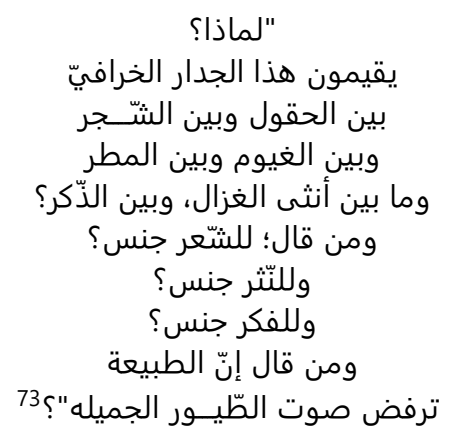

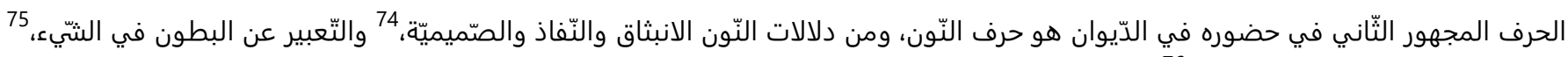

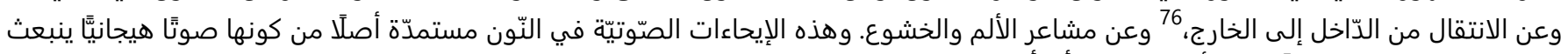

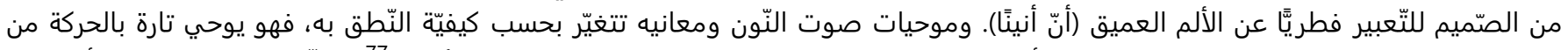

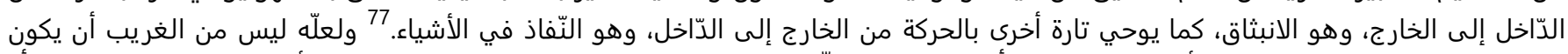

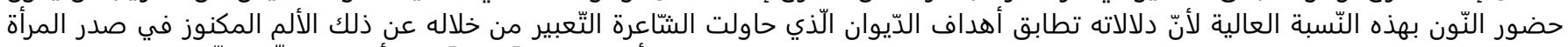

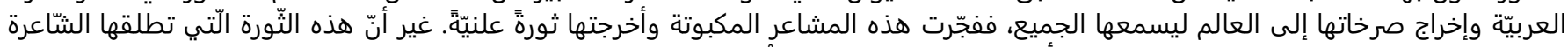

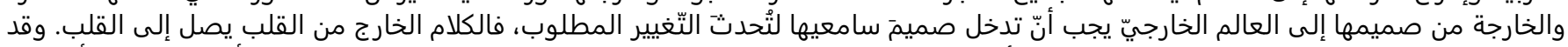

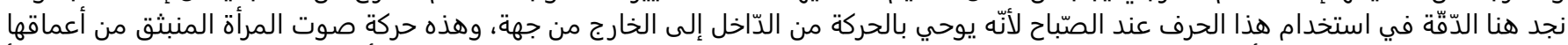

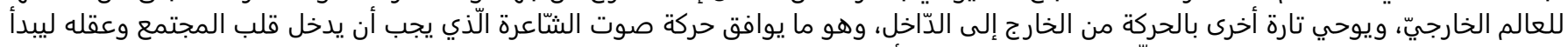

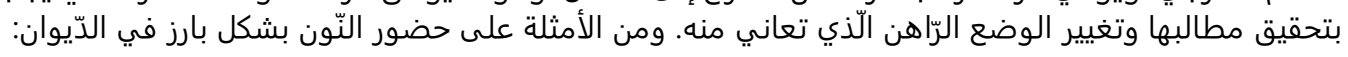

$$
\begin{aligned}
& \text { "إنّنّي مجنونة جدًّا } \\
& \text { وأنتِم عقلاء } \\
& \text { وأنا هاربة من جنّة العقل، } \\
& \text { وأنتم حكماء } \\
& \text { أشهر الصّيف لكم }
\end{aligned}
$$

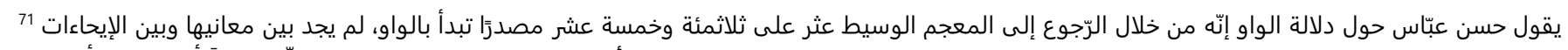

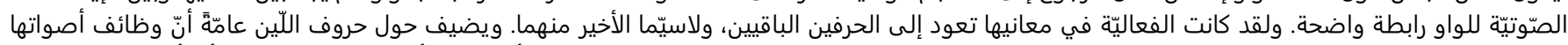

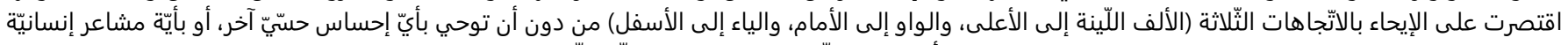

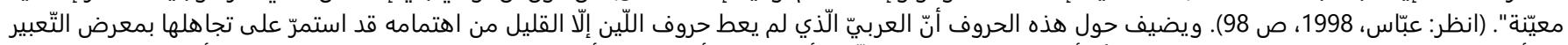

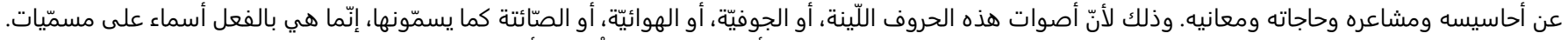

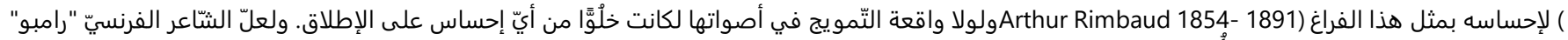

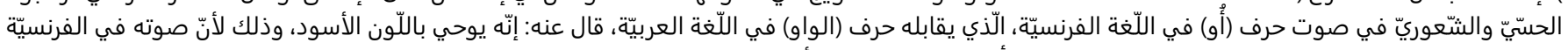

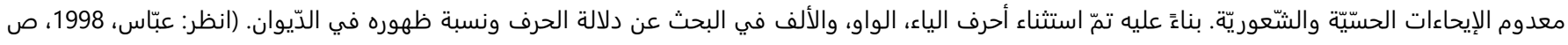
.(100

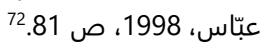

الصّباح، 1992، صبّاس، 1998، صن 19.73

عبّاس، 1998، 1992، ص 28.

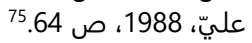

الأرسوزيّ، 1972، ص 1988، ص136.76.

عبّاس، 1998، ص ص 160، 77 


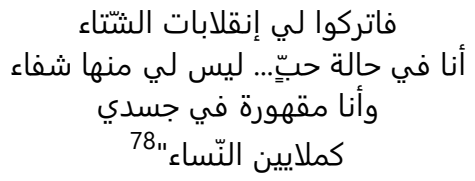

الحرف المجهور الثّالث من حيث نسبة حضوره في الدّيوان هو الميم، والرّابع هو الرّاء، ونجد أنّ الفرق بين نسبتي حضور الميم والرّاء صغير جدَّا بحيث

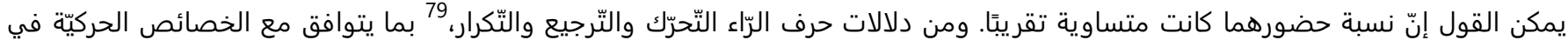

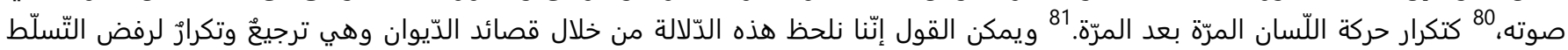

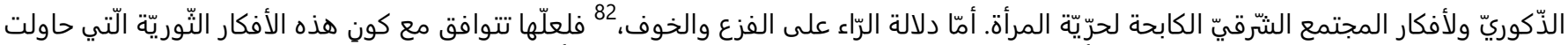

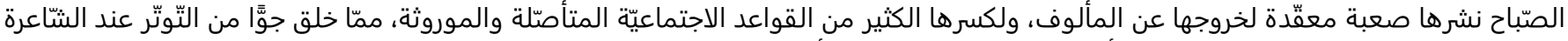
في ديوانها سببه الخوف من عرض هذه الأفكار على المجتمع. ومن الأمثلة الكثيرة لتكرار الرّاء عند الصّبّاح قولهاء المّاء

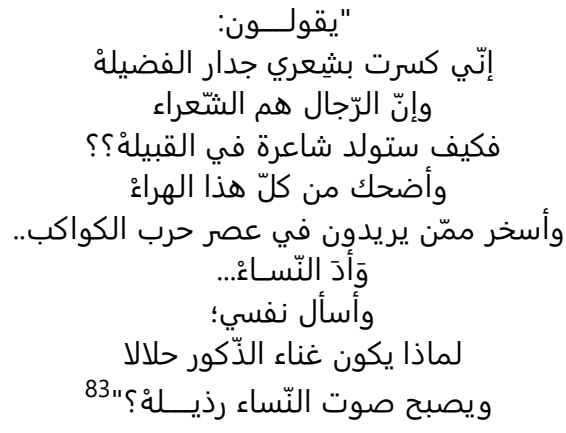

ومن الجدير ذكره في هذا الباب نسبة شيوع حروف اللّين المدّيّة أو الحركات الطّوال 84 بشكل واضح في الدّيوان، وخاصّة الألف والياء، والشِّعر الحديث

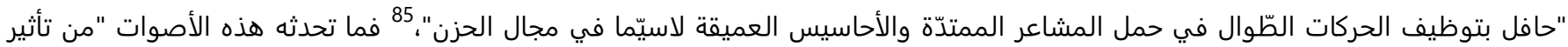

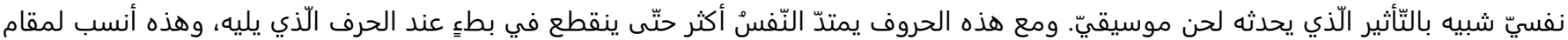

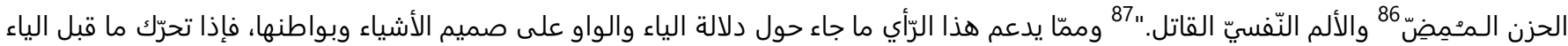

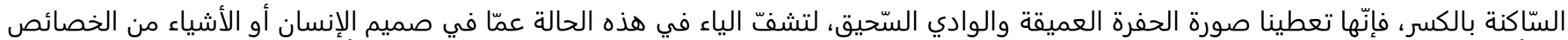

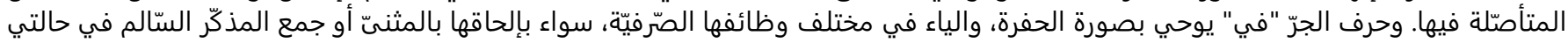

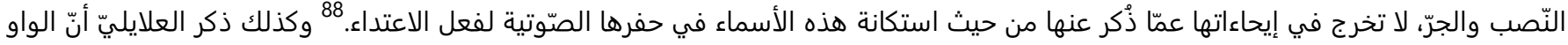

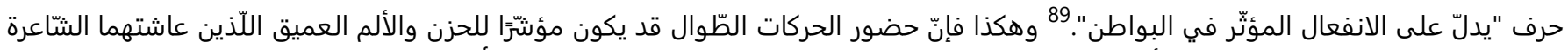

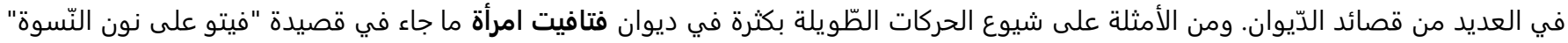

$$
\begin{aligned}
& \text { "يقولـــــــ }
\end{aligned}
$$

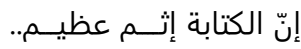

$$
\begin{aligned}
& \text { فلا تكتبـي. } \\
& \text { وإنّ الصّلاة أمام الحروفي... حرام } \\
& \text { فلا تقربـي. }
\end{aligned}
$$

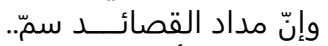

$$
\begin{aligned}
& \text { فإيّاك أن تشربي. }
\end{aligned}
$$

الصّباح، 1992، ص 1938 صبتاس 78

عبّاس، 1998، ص 1992، ص 28.

عبّاس، 1998، ص ص 1998 ص 80.

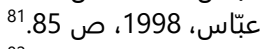

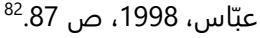

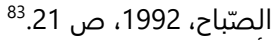

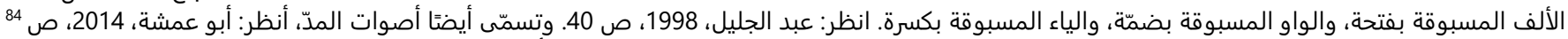

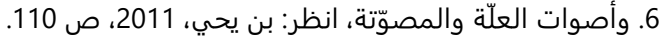

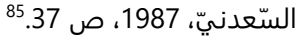

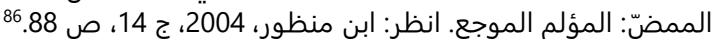

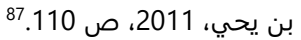

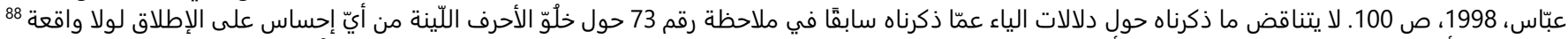

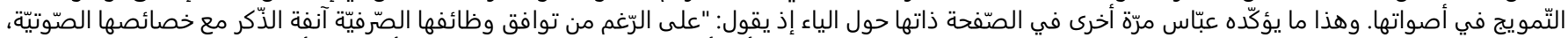

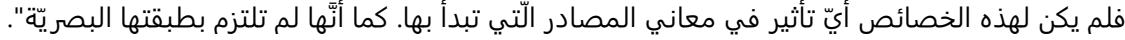

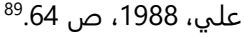




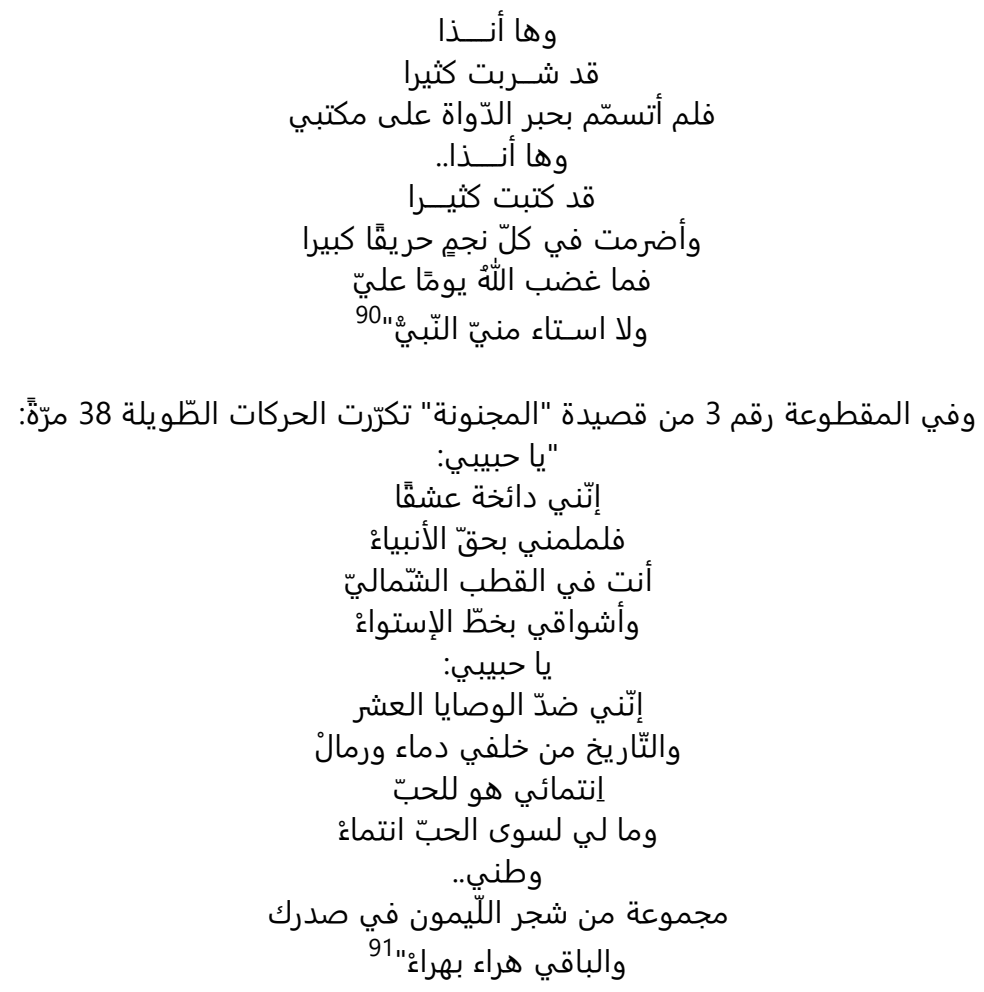

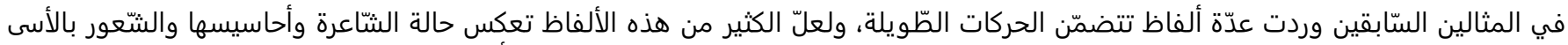

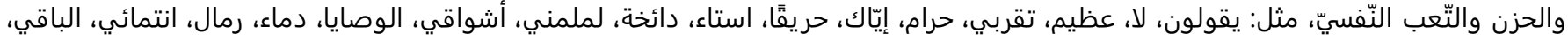

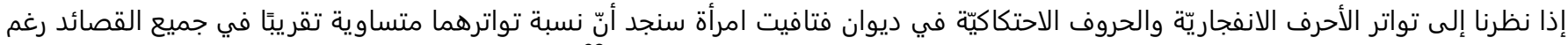

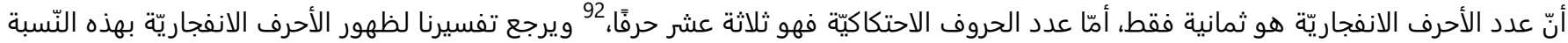

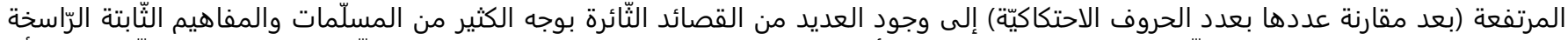

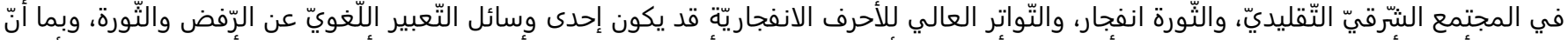

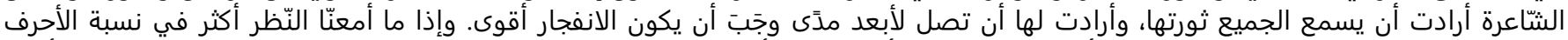

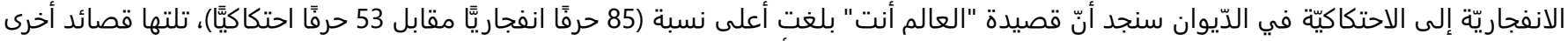

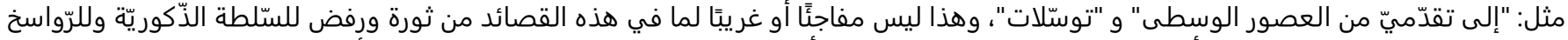

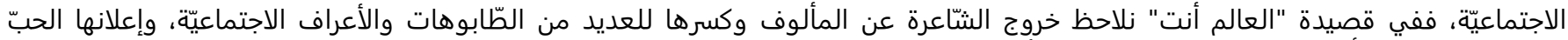

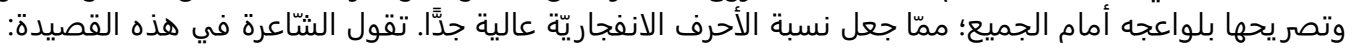

$$
\begin{aligned}
& \text { "خذ الخريطهْ } \\
& \text { ورتّبها كما تشاء } \\
& \text { فالقارّات أنت } \\
& \text { والبحار أنت. } \\
& \text { وأنا أنت. } \\
& \text { من اسمك تبدأ جغرافيّة المكانْ } \\
& \text { ومن عينيكَ تأخذ البحار ألوانها } \\
& \text { ومن ثغركَ يولد اللّيل والنّهاز } \\
& \text { ومن إيقاعات صوتك ئك } \\
& \text { ومن شرايين يديك }
\end{aligned}
$$

الصّباح، 1992، ص ص 1992، 16.

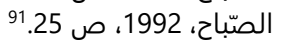

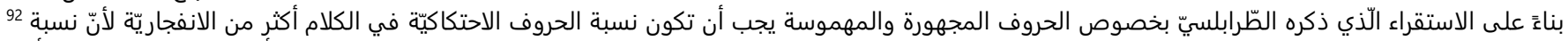

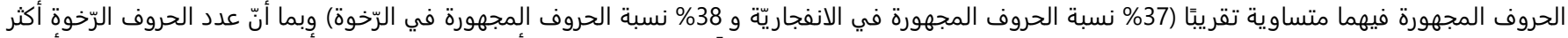

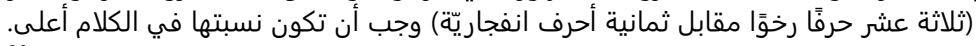

الصَّاح، 1992، ص ص 83. 


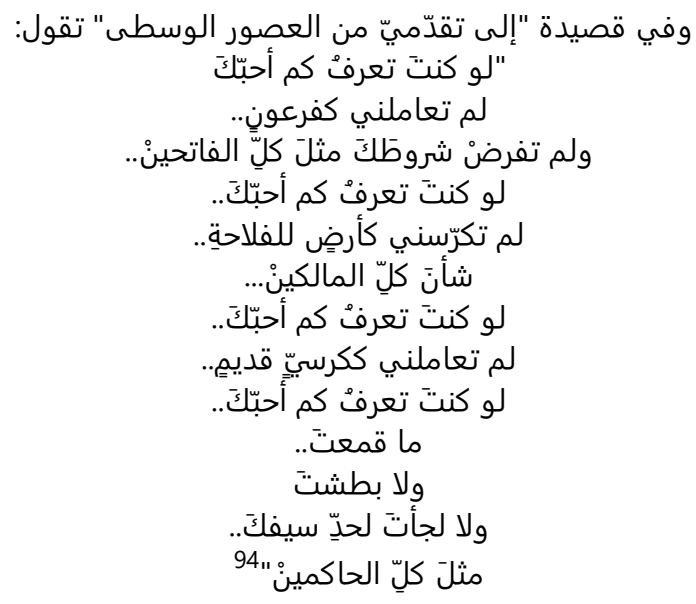

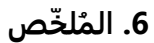

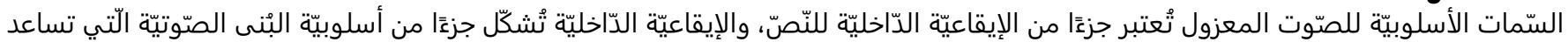
على كشف التّوظيف الصّوتيّ لتجسيد الخيال وتحقيق الصّورة في النّصّ.

المقياس الّذي اعتمدناه في تحليلنا للسّمات الأسلوبيّة للصّّوت المعزول في ديوان فتافيتافيت امرأة لسعاد الصّباح هو نسبة الأصوات المهموسة مقارنةً بالمجهورة من جهة، ونسبة الأصوات الانفجاريّة مقارنةً بالاحتكاكيّة من جهة أخرى، ومدى تجاوز هذه النّسب لنسبها في في الكلام العاديّ.

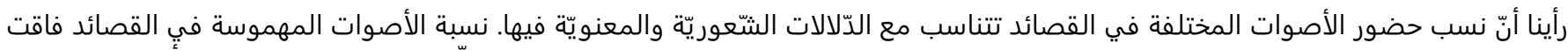

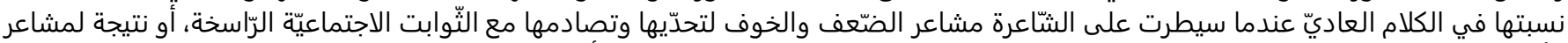

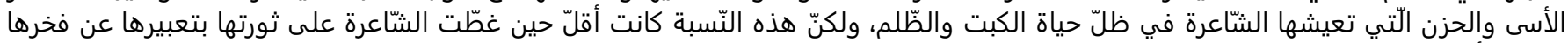

بوطنها أو بيئتها.

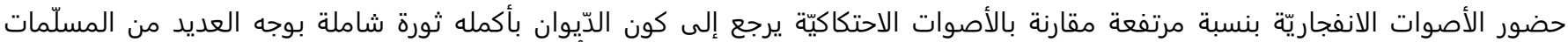

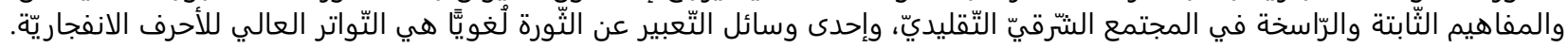

Funding: The author feels obliged to point out that this research did not receive any specific grant from funding agencies in the public, commercial, or not-for-profit sectors. The author of this article is solely self-funded.

Acknowledgements: This work would not have been possible without the kind support of my colleagues, friends, and family for their kind support and encouragement. I would also like to cordially thank the translator of this original manuscript who translated the text from Arabic to English, giving it a chance to internationality.

Conflicts of Interest: The author of this article declare that there is no conflict of interest whatsoever.

$$
\begin{aligned}
& \text { المراجع } \\
& \text { المراجع العربيّة: }
\end{aligned}
$$

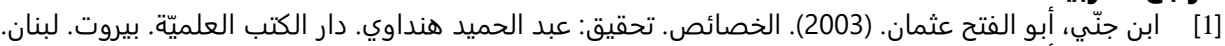

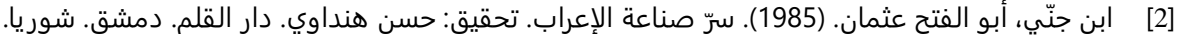

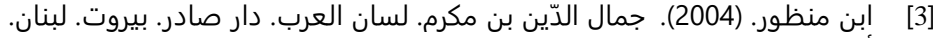

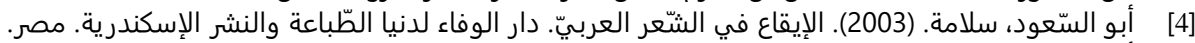

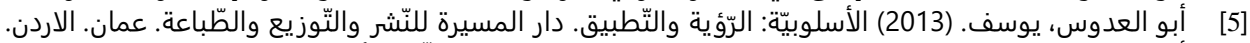

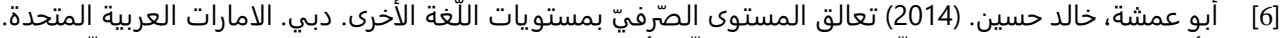

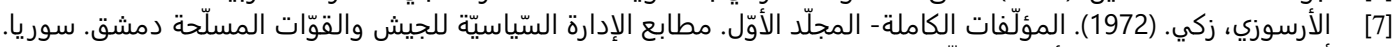

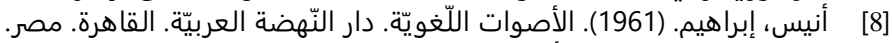

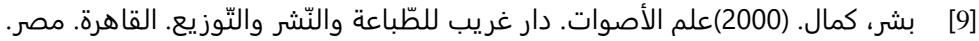

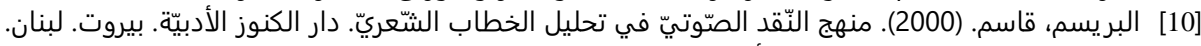

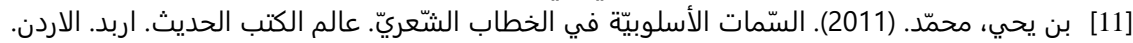

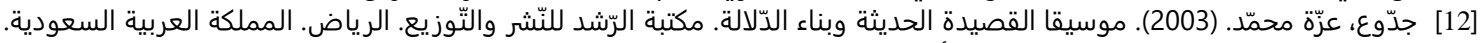

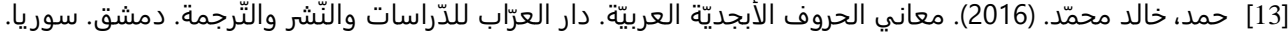

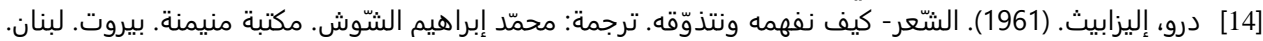

الصّباح، 1989، ص 71.0 
[15] السّعدنيّ، مصطفى. (1987) البنيات الأسلوبيّة في لغة الشّعر العربيّ الحديث. منشأة المعارف. الاسكندرية. مصر.

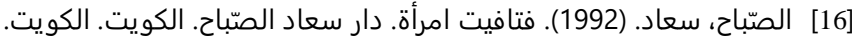

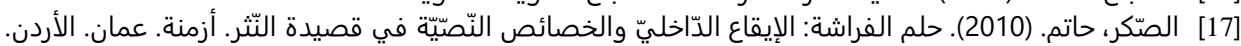

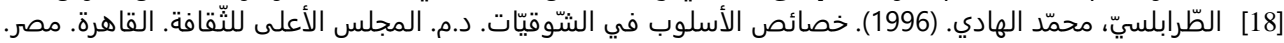

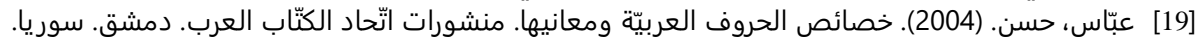

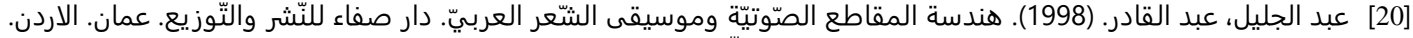

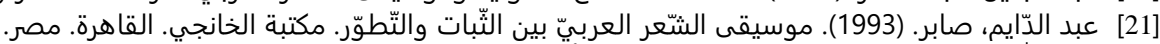

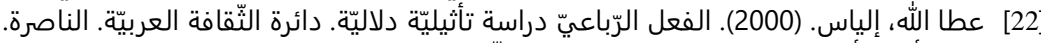

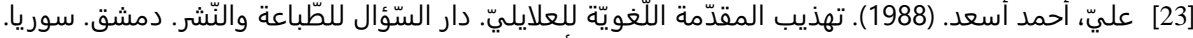

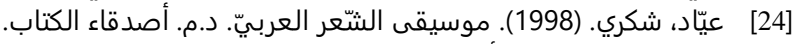

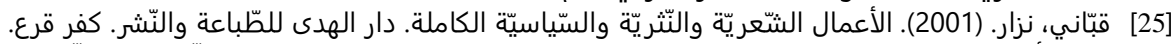

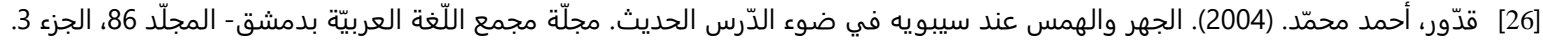

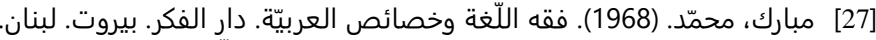

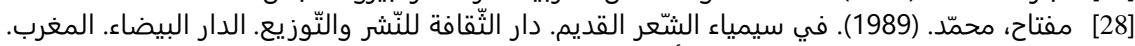

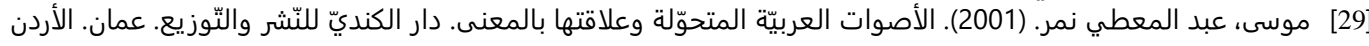

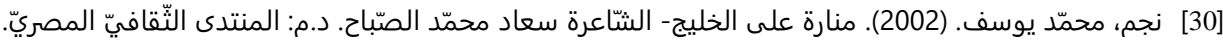

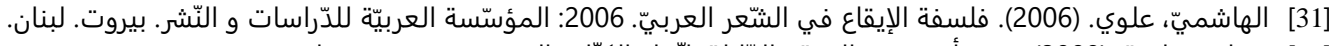

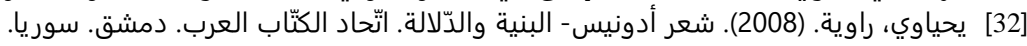

\section{English References}

[33] Hershev, B. (2008). Meter and Rhythm in the Modern Arabic Poetry. Jerusalem: Karmel Press

[34] Plaay, M \& Baraka, D. (1961-1995). Encyclopedia Hebraica. Geftim- Ramat Jan: Plaay-B Press.

[35] Bloomfield, L. (1954). Language. New York: Henry Holt.

[36] Richards, I. (1930). Principles of Literary Criticizm. New York: Harcourt, Brace \& Company, Inc. 